OPEN ACCESS

Edited by:

Lee Fah Yap,

University of Malaya, Malaysia

Reviewed by:

Abhik Saha

Presidency University, India

Christopher Dawson,

University of Warwick,

United Kingdom

${ }^{*}$ Correspondence:

Merrin Man Long Leong

xmerrinx@connect.hku.hk

Specialty section: This article was submitted to Molecular and Cellular Oncology,

a section of the journa

Frontiers in Oncology

Received: 16 November 2020

Accepted: 18 January 2021

Published: 25 February 2021

Citation:

Leong MML and Lung ML (2021) The Impact of Epstein-Barr Virus Infection on Epigenetic Regulation of Host Cell

Gene Expression in Epithelial and Lymphocytic Malignancies.

Front. Oncol. 11:629780.

doi: 10.3389/fonc.2021.629780

\section{The Impact of Epstein-Barr Virus Infection on Epigenetic Regulation of Host Cell Gene Expression in Epithelial and Lymphocytic Malignancies}

\author{
Merrin Man Long Leong ${ }^{1,2^{*}}$ and Maria Li Lung $^{3}$ \\ ${ }^{1}$ Division of Infectious Diseases, Department of Medicine, Brigham and Women's Hospital, Harvard Medical School, Boston, \\ MA, United States, 2 Department of Microbiology, Harvard Medical School, Harvard University, Boston, MA, United States, \\ ${ }^{3}$ Department of Clinical Oncology, University of Hong Kong, Hong Kong, Hong Kong
}

Epstein-Barr virus (EBV) infection is associated with a variety of malignancies including Burkitt's lymphoma (BL), Hodgkin's disease, T cell lymphoma, nasopharyngeal carcinoma (NPC), and $10 \%$ of cases of gastric cancer (EBVaGC). Disruption of epigenetic regulation in the expression of tumor suppressor genes or oncogenes has been considered as one of the important mechanisms for carcinogenesis. Global hypermethylation is a distinct feature in NPC and EBVaGC, whereas global reduction of H3K27me3 is more prevalent in EBVaGC and EBV-transformed lymphoblastoid cells. In BL, EBV may even usurp the host factors to epigenetically regulate its own viral gene expression to restrict latency and lytic switch, resulting in evasion of immunosurveillance. Furthermore, in $B L$ and $E B V a G C$, the interaction between the EBV episome and the host genome is evident with respectively unique epigenetic features. While the interaction is associated with suppression of gene expression in BL, the corresponding activity in EBVaGC is linked to activation of gene expression. As EBV establishes a unique latency program in these cancer types, it is possible that EBV utilizes different latency proteins to hijack the epigenetic modulators in the host cells for pathogenesis. Since epigenetic regulation of gene expression is reversible, understanding the precise mechanisms about how EBV dysregulates the epigenetic mechanisms enables us to identify the potential targets for epigenetic therapies. This review summarizes the currently available epigenetic profiles of several well-studied EBV-associated cancers and the relevant distinct mechanisms leading to aberrant epigenetic signatures due to EBV.

Keywords: Epstein-Barr virus, epigenetics, histone modifications, DNA methylation, nasopharyngeal carcinoma, EBV-associated gastric cancer, EBV-associated lymphomas 


\section{INTRODUCTION}

Epstein-Barr virus (EBV), also known as human herpesvirus 4, was the first human cancer-associated virus to be discovered (1). A wide range of lymphocytic and epithelial malignancies can be directly associated with EBV infection. Instead of progeny virus production via lytic infection, the virus preferentially infects human B-lymphocytes and epigenetically silences the expression of $\sim 80$ EBV lytic antigens, presumably by sensing MYC abundance, to maintain a B cell life-long latency $(2,3)$. This provides the host cell survival advantage to evade the host immunogenic responses. The latency programs established in EBV-associated B-cell or epithelial malignancies, including Burkitt's lymphoma (BL), Hodgkin's disease, T cell lymphoma, nasopharyngeal carcinoma (NPC), and $\sim 10 \%$ of cases of gastric cancer (EBVaGC), can be quite different, even within the same type of cancer (4).

The EBV latency proteins include six EBV nuclear antigens (EBNA1, EBNA2, EBNA3A/B/C, EBNA-LP), and three latent membrane proteins (LMP1, LMP2A/B) (5). Studies have demonstrated that some of these latency proteins are strongly associated with oncogenicity. For example, LMP1 has been considered as a classic oncogene for its essential role in primary B cell transformation $(6,7)$. Similarly, the LMP1 transformation properties, including anchorage-independent growth and invasiveness, could be observed in a SV40Timmortalized nasopharyngeal epithelial (NPE) cell line (NP69SV40T) (8). However, different from EBV-transformed B cells or NPC, the expression of LMP1 in EBVaGC is usually undetectable, suggesting EBV involves different tumorigenic mechanisms in different tissues.

Epigenetics refers to the heritable changes in gene expression independent of changes in the DNA sequence $(9,10)$. Dysregulation of epigenetic machineries can interrupt the normal expression of tumor suppressor genes (TSGs) and oncogenes, which may ultimately lead to tumorigenesis. Currently, the widely studied epigenetic alterations associated with tumorigenesis include DNA methylation, histone modification, and chromatin conformation alterations. In fact, the impact of EBV in epigenetic regulation is evident and it is involved in promoting development of different cancers. EBNA1, the latent protein involved in maintenance of the EBV episome, is detectable in all types of EBV-associated malignancies and is able to bind to a number of promoter regions of oncogenes and TSGs to regulate their expression in both lymphocytic and epithelial malignant cells (11-13). Another study showed that a subset of breast cancer patients was associated with EBV infection from whom a few critical TSGs were methylated including $B R C A 1 / 2, p 14, p 16$, and $h M L H(14,15)$. In contrast, hypermethylation of the tumor-related genes is more common in EBV-negative than in EBV-positive Hodgkin's lymphoma cases (16). When comparing the EBV-positive and -negative Burkitt lymphomas (BL) cell lines, the contribution of EBV to a specific methylome signature and expression profile associated with BL pathogenesis was reported (17). Although transformation of B lymphocytes by EBV resulted in large-scale hypomethylated blocks (18), the hypermethylation patterns in NPC and
EBVaGC could be observed $(19,20)$, suggesting the distinct epigenetic role of EBV in these cancers.

As the advanced sequencing techniques become more common, the epigenetic profiles including DNA methylation and histone modifications in EBV-associated cancer have been comprehensively investigated nowadays. Hence, this review summarizes and compares the epigenetic profiles of several extensively studied EBV-associated cancers, including NPC, EBVaGC, LCLs, and BL, and their different mechanisms contributing to the unique epigenetic signatures.

\section{EBV INFECTION CAN ALTER DNA METHYLATION PATTERNS}

DNA methylation usually occurs in $\mathrm{CpG}$ dinucleotides by covalently transferring a methyl group $\left(\mathrm{CH}_{3}\right)$ to the cytosine nucleotide, becoming 5 -methylcytosine $(5 \mathrm{mC})$. This process is catalyzed by a family of DNA methyltransferase (DNMT) enzymes (DNMT1, DNMT3a/c), utilizing S-adenosylmethionine (SAM) as the substrate for the methylation (21). While DNMT3a and DNMT3b, the de novo DNMTs, establish a new methylation pattern of unmodified DNA, DNMT1 maintains the DNA methylation pattern during daughter strand DNA synthesis (21). In contrast, the ten-eleven translocation (TET) enzyme can reverse the $5 \mathrm{mC}$ to cytosines by oxidizing the $5 \mathrm{mC}$ to form 5 hydroxymethylcytosine $(5 \mathrm{hmC})$, followed by thymine DNA glycosylase (TDG)-dependent base excision repair (BER) (22). The hypermethylation pattern frequently occurs in the CpG-rich segments, known as a CpG island (CGI). They are abundant in promoter regions, as evidenced by finding roughly $70 \%$ of mammalian gene promoters contain CGIs (23). These CGIs are usually unmethylated, allowing transcription initiation. Hypermethylated CGIs of promoters are strongly associated with the gene silencing and dysregulation of the methylation mechanisms is related to various cancer development (24).

\section{Global DNA Hypermethylation and the Contribution of LMP1 to TSG Silencing in NPC}

Our previous methylome study compared the tumor data from 11 solid NPC primary tumors, which harbored a significant hypermethylation pattern at the CGIs (19). Another methylcapture sequencing study also identified hypermethylation at the CGIs of some key TSGs (25). In fact, the promoter regions of several critical TSGs have been reported with hypermethylation and validated to be down-regulated in NPC including RASSF1 $(26,27)$, CDKN2A (28-30), MIPOL1 $(31,32)$, PTPRG $(33,34)$, RRAD (25, 35), THY1 (36, 37), PTEN (38, 39), CDH1 (40, 41), and $R A R \beta 2(42,43)$. A study using NPC cell lines demonstrated that the YYD domain at $\mathrm{COOH}$-terminal activation region 2 (CTAR2) of LMP1 is critical to activate the JNK signaling pathway leading to phosphorylation of c-Jun to form an AP-1 complex with c-Jun (homodimer) or c-Fox (heterodimer) to bind to the promoter region of DNMT1 and enhance the DNMT1 expression (44). The enhanced DNMT1 expression 
results in hypermethylation of the E-cadherin gene (CDH1) and suppresses its expression (44) (Figure 1). Likewise, another NPC study also showed that re-expression of LMP1 could enhance the expression of DNMT1 and DNMT3a/b, resulting in methylation of the CDH1 promoter and reduction of its expression (45). LMP1 was further shown to enhance the expression of DNMT3b through the NFKB pathway, with evidence of 655 binding to the DNMT3b promoter, resulting in hypermethylation of the PTEN promoter and, hence, silencing its expression (46) (Figure 1). In addition, the significance of LMP1 contributing to DNA methylation was further highlighted by a study in which overexpression of LMP1 in a NPC cell line induced expression of DNMT1 and DNMT3a/b; all these DNMTs are necessary to suppress RAR $\beta 2$ via promoter hypermethylation (42). Although this study also showed that the presence of LMP1 elevated the level of pRB and E2F1, which may be relevant to the enhanced expression of DNMTs, the connection of the Rb-E2F1 pathway to LMP1-mediated DNMTs activation was uncertain in NPC (42). Overall, these studies proposed the importance of LMP1 for the mechanisms regulating the aberrant DNA hypermethylation in NPC to suppress TSGs, as summarized in Figure 1.

\section{Global DNA Hypermethylation and the Contribution of LMP2A to TSG Suppression Through Gene Methylation in EBVaGC}

In contrast to NPC, LMP1 is usually not expressed in EBVaGC. Nevertheless, this solid tumor also harbors extensive DNA methylation. As reported by The Cancer Genome Atlas (TCGA), EBVaGC is characterized by a higher prevalence of DNA methylation than for other GC cancers. This is commonly known as the EBV-CpG island methylator phenotype (EBVCIMP) (47). When EBV infects an EBV-negative gastric cancer cell line with low methylation phenotype (MKN7), a DNA hypermethylation pattern similar to that observed in EBVaCG could be obtained (20), suggesting the important role of EBV in the development of the DNA hypermethylation pattern in EBVaGC. Hypermethylation and down-regulation of some TSGs were frequently reported in EBVaGC, including RASSFI (48), CDKN2A (48-56), IRF5 (57), TP73 (56, 58), CDK2AP2 (51, 52, 55, 56, 59), WNT5A (60), PTEN $(48,61)$, and CDH1 (55, 56, 62). Immunohistochemistry staining also showed the correlation

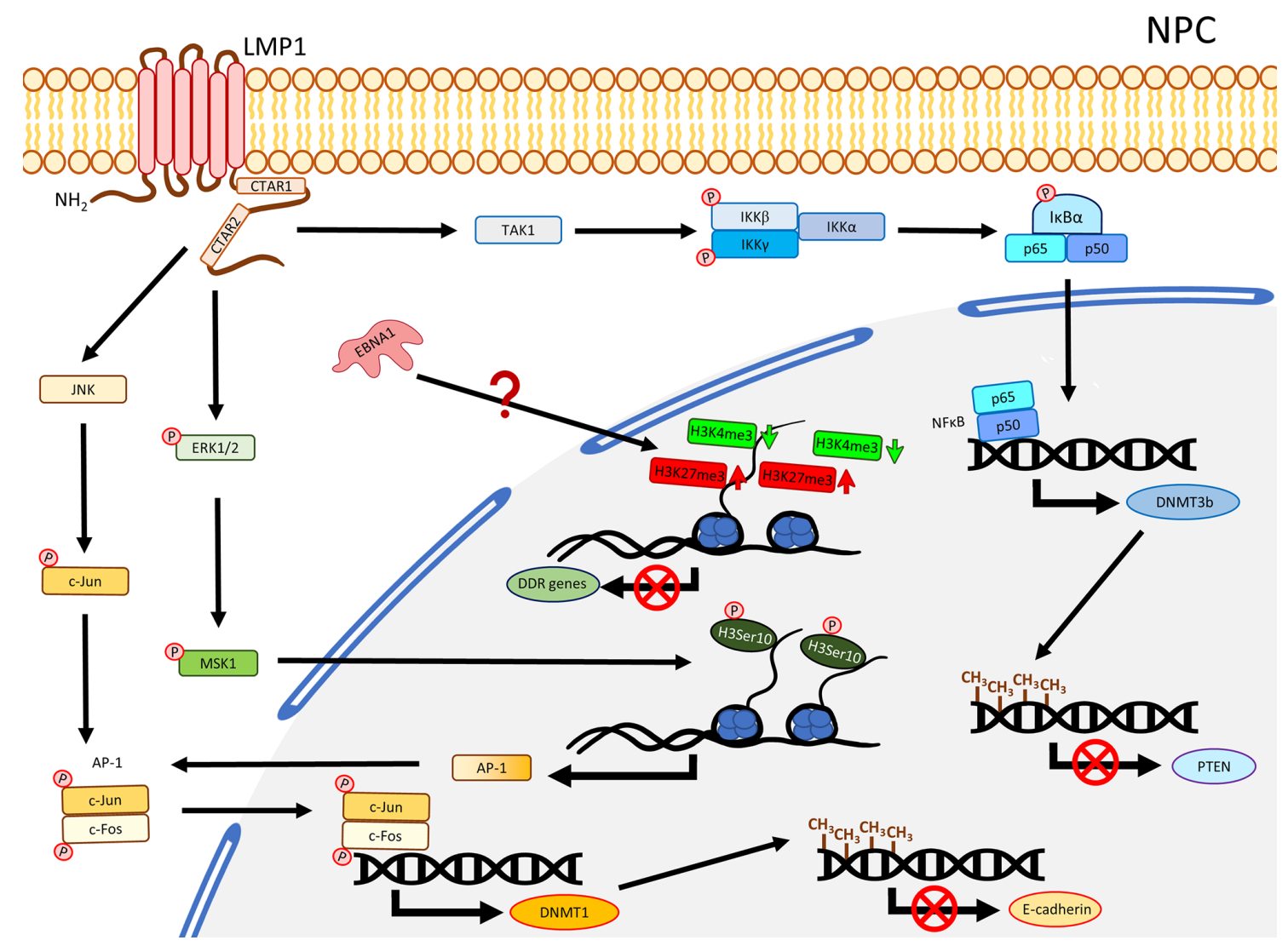

FIGURE 1 | A schematic diagram shows the impact of EBV on epigenetic dysregulation in NPC. LMP1 activates JNK and NFkB signaling pathways to enhance expression of DNMTs, resulting in promoter DNA hypermethylation in the TSGs including CDH1 (encoding E-cadherin) and PTEN. LMP1 may also promote phosphorylation of ERK1/2, resulting in phosphorylation of H3Ser10 to activate the expression of AP-1. Up-regulation of EBNA1 inhibits DDR genes expression probably through dysregulating bivalent switches in NPE cell lines. 
of DNMT1 over-expression. In EBVaGC, EBV contributes to the EBV-CIMP via enhancing DNMT1 expression (63). By infecting $\mathrm{EBV}$ into an EBV-negative GC cell line, Hino and colleagues showed that LMP2A induced phosphorylation of STAT3 to enhance the expression of DNMT1, leading to silencing of PTEN by promoter hypermethylation in an IL-6 independent manner (61) (Figure 2). The role of LMP2A to induce DNMT3a was further confirmed by over-expressing LMP2A in an EBVnegative GC cell line (64). This study demonstrated that LMP2A induces DNMT3a via phosphorylation of ERK to hypermethylate the promoter and first exon of aquaporin 3 (AQP3), resulting in down-regulation of AQP3 (64) (Figure 2). Since AQP3 was demonstrated to be involved in tumor metastasis and invasion in breast cancer (65), down-regulation of AQP3 in EBVaGC may explain why EBVaGC has a better prognosis compared with other non-EBV-associated GCs (66). Another study infecting EBV in a SV40 immortalized gastric mucosal cell line (GES1) and an EBV-negative GC cell line (MKN7) identified that EBV inhibited the TET family genes, in particular TET2, to protect DNA from demethylation in the host cells (67) (Figure 2). A panel of seven human miRNAs was also shown to be up-regulated in the EBV-infected cells (67). When BARF0, LMP2A, or the induced human miRNAs were over-expressed, the expression level of TET2 are significantly suppressed (67), highlighting the involvement of LMP2A in suppression of DNA demethylation. The study also showed that depletion of TET2 without EBV infection was not able to induce de novo methylation, whereas knocking down TET2 in EBV-infected cells largely induced de novo DNA methylation, indicating TET2 functions as a resistance factor against DNA methylation instead of a contribution factor. Therefore, the de novo DNA methylation is likely contributed by EBV (67). To date, the mechanisms about how EBV regulates the DNA methylation in GC are still not fully understood, but the current knowledge summarized here suggests that EBV regulates the DNA methylation mechanisms in the host cell mainly through LMP2A to activate DNMT1/3a and suppress TET2 (68), as summarized in Figure 2.

\section{EBV Transformation of B Cells Is Associated With Hypomethylation of B-Cell Activation Antigens and Hypermethylation of Certain TSGs}

EBV infection in B cells is not associated with global DNA hypermethylation. Instead, hypomethylation is commonly observed. EBV-infected primary B cells were shown to undergo demethylation at the promoter regions of a significant number of genes involving B cell activation such as CD19, CD79a, BLK, and FCER2 (69). Also, the hypomethylation in B cells took place after 24-h post EBV infection, when proliferation started, and many of the hypomethylated domains associated with $B$ cell activation are enriched with Pol II and a NFKB subunit p65 (69), suggesting EBV-associated demethylation induces B cell activation genes through NFKB activity. Although apparent global

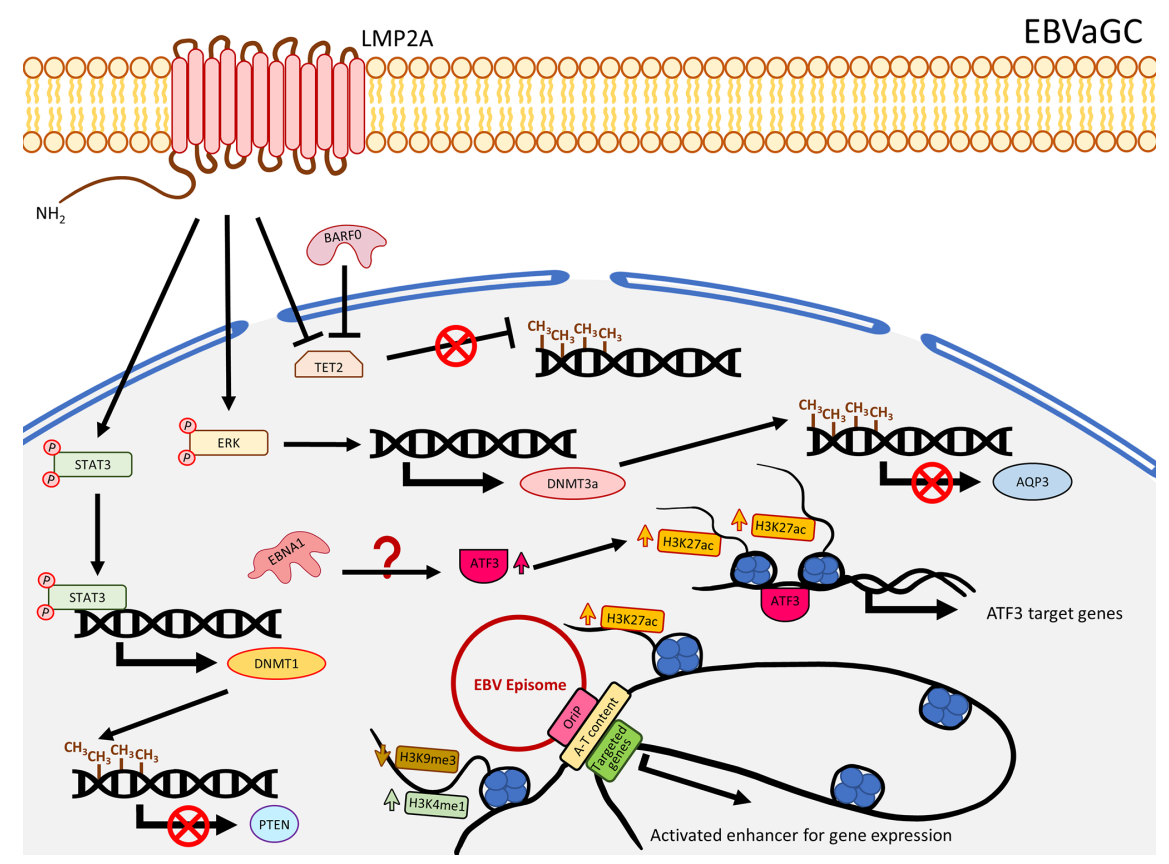

FIGURE 2 | A schematic diagram shows the impact of EBV on epigenetic dysregulation in EBVaGC. LMP2A inhibits TET2 and activates STAT3 and ERK signaling pathways to enhance expression of DNMTs, resulting in promoter DNA hypermethylation to suppress gene expression including PTEN and AQP3. EBNA1 enhanced the expression of ATF3, which functions as a transcription factor, to promote target gene expression, characterized by gain of H3K27ac. EBV can also interact with the host genome, where A-T content is enriched as well as H3K4me1 and H3K27ac, and reduced H3K9me3 levels to promote gene expression. 
hypermethylation phenotype in EBV-transformed B cells is not frequently observed $(18,69,70)$, notable methylation patterns in some key TSGs are evident (71). By comparing peripheral primary B cells and the corresponding EBV-transformed B cells, Saha and colleagues showed that EBV infection resulted in four methylation patterns for the TSGs, namely gain of methylation, loss of methylation, distinct methylation, and fluctuating methylation (71). Among these groups, 40 TSGs were classified as being in the gain of methylation group and some of them were further validated to be down-regulated in the EBV-infected B cells, including $A T M$, $C D K N 1 A / B, C D K N 2 A, T P 53, T P 73$, and $R b$ (71). Furthermore, at the mRNA level, DNMT3a/b/L and a group of HDACs were shown to be up-regulated in EBV-induced LCLs, suggesting EBV-infected primary B cells may specifically recruit a DNMT3 complex to regulate the TSG expression. Moreover, infection of EBV in B cells resulted in recruitment of a DNMT complex to the promoter of ID3 to inactivate the expression by hypermethylation. This phenotype was rescued when LMP1 was depleted or when the cells were treated with NFKB inhibitor, suggesting the downregulation of ID3 possibly through a LMP1-NFKB-mediated mechanism (17) (Figure 3). Similar to LCLs, when comparing to normal germinal center B cells, Burkitt and follicular lymphoma exhibited genome-wide hypomethylation patterns (72). When further comparing EBV-positive and -negative Burkitt lymphoma (BL) cell lines, a distinct distribution of methylated regions was identified. In EBV-positive BL cell lines, while hypomethylation in promoter regions is more common, hypermethylated regions are usually distant from transcriptional start sites (TSS) (17). Another study by over-expressing EBNA3C in an EBV-negative BL cell line, $\mathrm{BJAB}$, demonstrated that EBNA3C induced DNMT1 protein expression and EBNA3C could interact with DNMT1 (73). A recent functional study similarly illustrated that over-expression of EBNA3C could induce DNMT1 and DNMT3a expression, though the effect of DNMT1 was not obvious (74). The enhanced expression of DNMT3a could also be observed in LCLs, when compared with BJAB. This study further showed that the expression of RASSF1 was down-regulated by promoter hypermethylation in LCLs and EBNA3C-over-expressing BJAB (74), suggested EBNA3C down-regulated RASSF1 through enhancing DNMT activity to methylate the RASSF1 promoter. The EBV-mediated up-regulation of DNMT3a was further supported by an observation of an up-regulation of DNMT3a in EBV-infected germinal center-derived B cells and HL cell lines, even though DNMT1 and DNMT3b were shown to be down-regulated (75). The above studies emphasize that LMP1 and EBNAs are essential in the DNMT-mediated host gene expression regulation. The effects on DNMTs expression in different EBV-associated lymphomas are varied with the only consistency being that EBV infection in peripheral primary $\mathrm{B}$ cells, germinal center-derived B cells, LCLs, and EBNA3C-overexpressing BL cell lines indistinguishably showed an increased expression of DNMT3a (Figure 3).

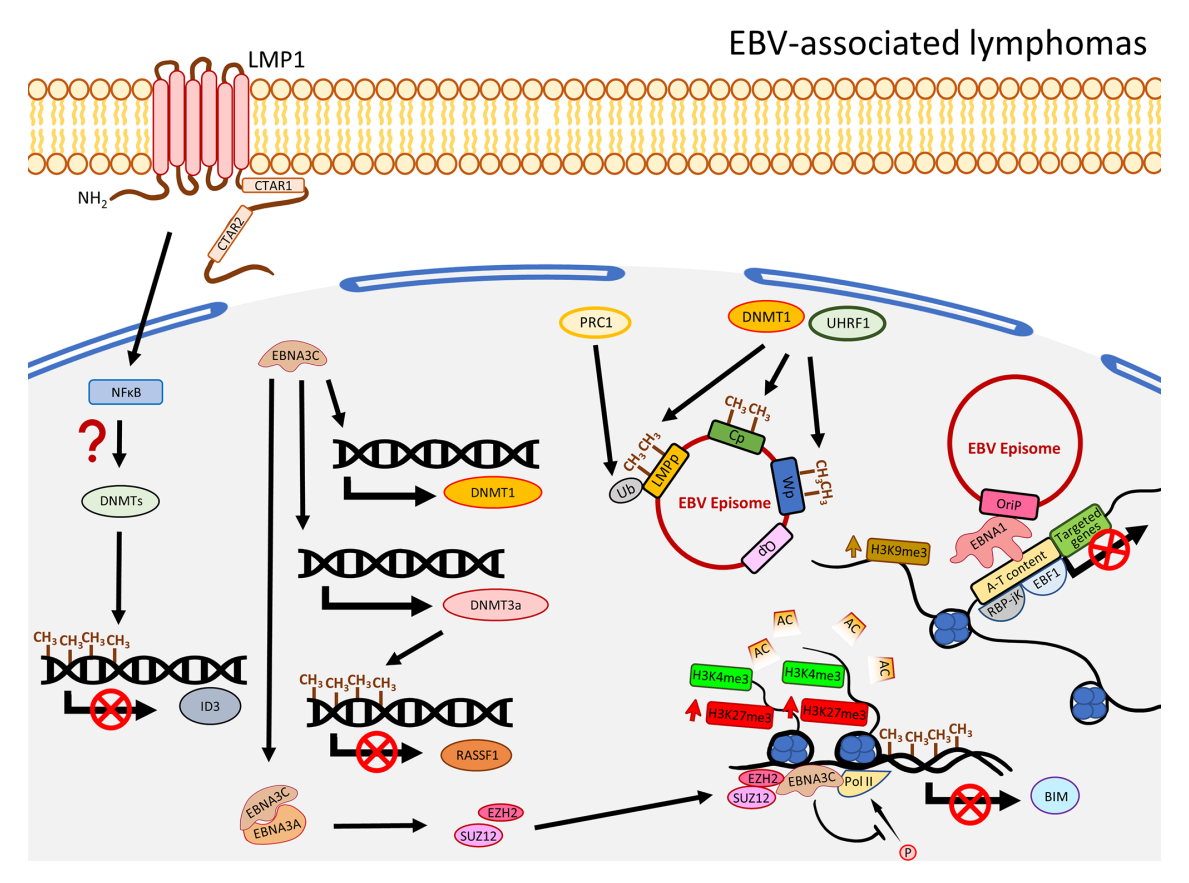

FIGURE 3 | A schematic diagram shows the impact of EBV on epigenetic dysregulation in EBV-associated lymphomas. LMP1 and NFאB are required to suppress the expression of ID3 via promoter methylation by a recruitment of the DNMT complex. EBNA3C promotes expression of DNMT3a to induce DNA methylation, resulting in suppression of gene expression including RASSF1. EBNA3C also interacts with EBNA3A to regulate the histone bivalent switch to recruit EZH2 and SUZ12 to the BIM promoter to regulate the expression, with evidence of the relevant promoter methylation. The EBV C promoter (Cp), W promoter (Wp), and LMP promoter (LMPp) are restricted by the host factors, including DNMT1 and UHRF1, through DNA methylation, or mono-ubiquitination of the LMPp by PRC1 (Ub: H2AK119Ub1). The interactions of EBV and host genome, through EBNA1 tethering, are associated with gene silencing and enriched with enhanced H3K9me3, A-T content, RBP-jK, and EBF1. 
In addition to regulating the host gene expression, EBV could also usurp the host factors to modulate its own gene expression. A recent study utilized a genome-scale CRISPR-Cas9 screen to identify that UHRF1 and DNMT1 are critical to restrict EBNAs and LMPs expression through DNA methylation in the C promoter (Cp) and LMP promoters (LMPp) to maintain latency I in $\mathrm{BL}$ cells (76). The same study also showed the importance of the subunits of PRC1 to suppress LMPp and Cp by histone 2A lysine 119 mono-ubiquitination (H2AK119Ub), and further demonstrated the viral DNA methylation was initiated by DNMT3B and maintained by DNMT1 (76). On the other hand, the significant role of MYC, as a lytic repressor by inhibiting oriLyt association with the BZLF1 promoter, was demonstrated. Taken together, it seems that EBV not only regulates the host gene expression, it also interplays with the host factors to epigenetically regulate its own viral gene expression in order to restrict the latent and lytic switch. Limiting the expression of the latent and lytic oncoproteins makes it possible for the infected B cells to evade immune surveillance and contribute to EBV pathogenesis and oncogenesis.

\section{EBV INFECTION RESULTS IN ABERRANT HISTONE MODIFICATIONS}

Aberrant histone modification is another epigenetic feature associated with cancer development $(77,78)$. The N-terminal tails of histones are subject to a variety of post-translational modifications (PTMs) including methylation, acetylation, ubiquitylation, sumoylation, and phosphorylation on specific residues $(79,80)$. The side chains of lysine on histone $\mathrm{H} 3$ is a site where various modifications frequently occur (81). The welldocumented histone modifications include, but are not limited to, acetylation of $\mathrm{H} 3$ at lysine 27 (H3K27ac), trimethylation of $\mathrm{H} 3$ at lysine 4 (H3K4me3), at lysine 27 (H3K27me3), and at lysine 9 (H3K9me3). Lysine acetyltransferases (KATs), also known as histone acetyltransferases (HATs), are the enzymes that recruit acetyl groups to histone lysine residues. Introducing a acetyl group to the residue neutralizes the positive charge on the lysine and weakens the electrostatic interaction between negatively charged DNA and histones, resulting in loosening of chromatin structure to be accessible to transcription factors (TFs) $(78,79)$. Hence, H3K27ac is usually localized to the enhancer and promoter regions and is associated with active transcription $(78,82)$. Histone deacetylases (HDACs), in contrast, are responsible for removal of the acetyl group (78). The balance activities between HATs and HDACs maintain the dynamic acetylation equilibrium and, hence, regulate the gene expression $(83,84)$. Unlike acetylation, methylation of a histone does not alter the charge. Depending on the site and degree of methylation, methylation of a histone can result in either activation or repression of gene expression. For instance, the $\mathrm{H} 3 \mathrm{~K} 4 \mathrm{mel}$ and $\mathrm{H} 3 \mathrm{~K} 4 \mathrm{me} 3$ are transcriptional activation marks, while $\mathrm{H} 3 \mathrm{~K} 9 \mathrm{me} 3$ and $\mathrm{H} 3 \mathrm{~K} 27 \mathrm{me} 3$ are typically found in the proximity of transcription suppressive sites (85). Similar to the DNA methylation, SAM was used as the methyl group donor by histone methyltransferases (HMTs), and is removed by histone demethylases (HDMs) (86). Among the HMTs, the polycomb repressive complex 2 (PRC2) is widely known as an $\mathrm{H} 3 \mathrm{~K} 27$ methyltransferase, which is composed of four core subunits including EZH1/2, SUZ12, EED, and RbAp46/48 (87, 88). Notably, H3K4me3 and H3K27me3 are reported to coexist in the promoters as a bivalent mark to fine-tune gene expression (89-91). The bivalent domains were first described in embryonic stem cells (ESCs) by Bradley and colleagues to regulate developmental gene expression (90). They observed that expression of some developmental genes was low or not expressed at all with the presence of the bivalent marks. However, the expression of the corresponding genes was elevated upon differentiation and exhibited reduction of $\mathrm{H} 3 \mathrm{~K} 27 \mathrm{me} 3$ in the bivalent domains. It was suggested that the bivalent domains silenced developmental genes in ESCs, while keeping them poised for activation by loss of H3K27me3 (90). In addition to regulating the developmental gene expression, deregulation of the bivalent marks is also associated with a variety of cancers (91-94). Phosphorylation of histone H3 at Ser 10 (H3Ser10), a marker of mitosis, is critical for chromosome condensation, which was previously shown to be regulated by mitogen- and stress-activated kinase 1 (MSK1) (95-97). Phosphorylation of H3Ser10 (pH3Ser10) was also demonstrated to be crucial for cell transformation $(96,98)$, implicating the association of pH3Ser10 in cancer development.

\section{Elevation of H3K27me3 and the Modulation of Gene Expression via Histone Modification in NPC}

By comparing NPC tissues and the adjacent non-tumor sites in the nasopharynx, a study showed that the level of H3K27me3 was significantly higher in NPC and positively correlated with tumor metastasis, advanced clinical stage, chemoradioresistance, and survival time (99). The level of H3K27me3 was, hence, proposed as a biomarker for NPC patient survival and chemo-radioresistance (99). The elevated level of $\mathrm{H} 3 \mathrm{~K} 27 \mathrm{me} 3$ is possibly attributable to the enhanced activity of a PRC2 subunit, EZH2, in NPC (100). A ChIP-Seq study using NPC tumor tissues and xenografts targeting H3K27ac identified a distinct group of super enhancers (SE), among which an oncogene, ETV6, was further demonstrated to be up-regulated and correlated with poor survival in NPC patients (101). Also, the enhancer H3K27ac signals were enriched in NFKB-p65 motif (101). Since it is well-reported that the NFKB pathway is constitutively activated by LMP1 in NPC, it is possible that LMP1 regulates the $\mathrm{H} 3 \mathrm{~K} 27 \mathrm{ac}$ enhancer near NFKB-p65 promoter to activate the NFKB pathway. Another study revealed that there was a positive correlation between LMP1 and $\mathrm{pH} 3 \mathrm{Ser} 10$. A significantly higher level of pH3Ser10 in the poorly differentiated NPC tissues compared with chronic nasopharygitis tissues and normal nasopharynx tissues was observed (102). The same study further showed that over- 
expression of LMP1 in an NPC cell line increased the level of pERK1/2, pMSK1, pH3Ser10, and is associated with increased AP-1 promoter activity. Suppression of ERK1/2 and MSK1 by a small inhibitor and shRNA reduced the level of pH3Ser10 and AP-1 promoter activity (102), suggesting LMP1 regulates pH3Ser10 though the ERK/MSK1 pathway to promote AP-1 expression (Figure 1). As AP-1 was also demonstrated to regulate DNMT1 expression for methylation of the E-cadherin promoter in the presence of LMP1, it is possible a cross-talk exists in which LMP1 enhances the expression of AP-1 through phosphorylation of H3Ser10 at the promoter of AP-1, providing sufficient AP-1 for JNK/AP-1 pathway to up-regulate DNMT1 (Figure 1). In addition, our previous ChIP-Seq study comparing two pairs of EBV-positive and -negative NPE cell lines illustrated that EBV infection dysregulated histone bivalent switches, showing reduction of $\mathrm{H} 3 \mathrm{~K} 4 \mathrm{me} 3$ and gain of $\mathrm{H} 3 \mathrm{~K} 27 \mathrm{me} 3$, to suppress DNA damage repair (DDR) gene expression in a methylation-independent manner (103). The same study further showed that over-expression of EBNA1 could inhibit the expression of DDR genes (103). It seems that EBV could dysregulate the histone modifications in the precancerous host cells to suppress the key cancer-related genes without the involvement of DNA methylation. Nevertheless, more studies are needed to ascertain the direct contribution of EBNA1 to regulate the bivalent switches and, hence, suppress DNA damage repair genes in NPC. Furthermore, the de novo methylated loci identified from NPC remarkably overlap with the bivalent marks derived from human ESCs (19), implicating the possible correlation of bivalent marks and DNA methylation in NPC development.

\section{Redistribution of Histone Marks and Interaction of the EBV Episome With the Host Cell Genome Is Associated With Activation of Host Cell Gene Expression in EBVaGC}

A ChIP-Seq study analyzing H3K4me1, H3K4me3, H3K27ac, $\mathrm{H} 3 \mathrm{~K} 9 \mathrm{me} 3$, and $\mathrm{H} 3 \mathrm{~K} 27 \mathrm{me} 3$ showed that EBV infection in GC cell lines redistributed these histone marks in the promoter and enhancer regions (68). While the repressive mark H3K27me3 was shown to be higher in NPC (99), Atsushi et al. demonstrated that EBV infection in GC cell lines significantly reduced $\mathrm{H} 3 \mathrm{~K} 27 \mathrm{me} 3$ level around the TSS (68), consistent with another EBVaGC ChIP-Seq study showing EBV infection rarely increased $\mathrm{H} 3 \mathrm{~K} 27 \mathrm{me} 3$ signal in the promoter regions (104). Furthermore, they identified EBV infection significantly contributed to gain of $\mathrm{H} 3 \mathrm{~K} 27 \mathrm{ac}$ in the enhancer regions and those simultaneously associated with reduction of $\mathrm{H} 3 \mathrm{~K} 9 \mathrm{me} 3$ or unchanged level of $\mathrm{H} 3 \mathrm{~K} 27 \mathrm{me} 3$ are positively correlated with gene expression (68). The enhancer activated genes were significantly enriched with some cancer-related pathways, involving in cell proliferation and differentiation (68). The elevated H3K27ac signal may be due to the up-regulation of EP300 and down-regulation of HDACs in the EBV-infected GC cell lines, as shown in an RNA-Seq study (68), suggesting EBV dysregulates the balance of HAT (EP300) and HDACs, and consequently contributing to up-regulation of $\mathrm{H} 3 \mathrm{~K} 27 \mathrm{ac}$ signals for tumorigenesis (Figure 2). The importance of EBV-regulated $\mathrm{H} 3 \mathrm{~K} 27 \mathrm{ac}$ in GC cells was further emphasized by a recent study showing that EBV infection in MKN7 increased the expression of ATF3, and a ChIP-Seq analysis further showed that the binding sites of ATF3 are associated with enhanced H3K27ac signals (105). The neighboring genes of ATF3 binding sites were suggested to be ATF3 target genes. When ATF3 was knocked down in EBVaGC cell lines (SNU719 and NCC24), these ATF3 target genes were down-regulated, resulting in growth suppression and apoptosis (105). The upregulation of ATF3 may be contributed by EBNA1, as evident by an EBNA1 over-expression analysis in MKN7 (105) (Figure 2). Another ChIP-Seq study identified the correlation of promoter DNA methylation and histone modifications in EBV-infected GC cell lines (104). Sayaka et al. analyzed DNA methylation and alteration of $\mathrm{H} 3 \mathrm{~K} 4 \mathrm{me} 3, \mathrm{H} 3 \mathrm{~K} 27 \mathrm{ac}$, and $\mathrm{H} 3 \mathrm{~K} 27 \mathrm{me} 3$, revealing that although a number of genes were methylated after EBV infection, the expression of these DNA methylation-induced genes was not completely silenced, depending on if they were classified as DNA methylation-sensitive genes or DNA methylation-resistant genes (104). While the whole promoter in DNA methylation-sensitive genes is methylated to suppress gene expression, DNA methylation-resistant genes acquire DNA methylation merely around the TSS and retain gene expression after EBV infection. The gene ontology analysis showed that the DNA methylation-sensitive genes are enriched with regulation of cell differentiation, migration, proliferation, and cell adhesion, but DNA repair and DNA metabolic processes are enriched for DNA methylation-resistant genes (104). From the same study, they also found that the TSS in DNA methylation-resistant genes was protected from methylation by active histone marks (H3K4me3 and $\mathrm{H} 3 \mathrm{~K} 27 \mathrm{ac}$ ) allowing them to be expressed, including the DDR genes ( $M L H 1, M S H 2$, and MSH6), but loss of these marks makes them susceptible to DNA methylation (104). It is noteworthy that DNA methylation-sensitive genes, including $C D K N 2 A, C D H 1$, and $R H O B$, are associated with loss of $\mathrm{H} 3 \mathrm{~K} 27 \mathrm{me} 3$ or reduction of $\mathrm{H} 3 \mathrm{~K} 4 \mathrm{me} 3$ and $\mathrm{H} 3 \mathrm{~K} 27 \mathrm{ac}$ (104). On the whole, it is plausible that EBV-associated DNA methylation could be modulated by redistribution of these histone marks to regulate the gene expression.

The EBV viral genome predominantly persists in the nucleus in a circular episomal state instead of integration into the host genome, suggesting that EBV episome may interact with the host genome to, in a certain extent, influence gene expression. Interaction of EBV episome and the host genome, in fact, could result in redistribution of histone marks. Using a panel of 14 GC cell lines, including three EBV positive, two immortalized gastric epithelial cell lines, and EBV-positive primary GC tissues, a recent chromosome conformation capture combined with high-throughput sequencing ( $\mathrm{Hi}-\mathrm{C}$ ) study showed that the EBV genome, in particular the oriP 
region, preferentially associated with human chromosomes 2,3 , 4, 6, 7, and 13, and these EBV-interacting regions usually exhibited higher A-T content, reduced $\mathrm{H} 3 \mathrm{~K} 9 \mathrm{me} 3$, as well as higher H3K27ac or H3K4me1 signals (106) (Figure 2). This study further showed that the domain and loop structure alterations by EBV infection could induce cancer-related gene expression including KLF5, TGFBR2, and MZT1 (106), suggesting the role of $\mathrm{EBV}$ in the regulation of gene expression through histone modification and chromatin conformation alteration.

\section{Global Reduction of H3K9//27me3 and H4K20me3 in EBV-Transformed LCLs Is Associated With Host Cell Gene Suppression in BL}

The global level of H3K27me3 in LCLs is different from NPC, but similar to EBVaGC, showing significant reduction (107). The global reduction of $\mathrm{H} 3 \mathrm{~K} 27 \mathrm{me} 3$ may be due to the LMP1mediated up-regulation of a histone demethylase, Jumonji Domain-Containing Protein 3 (JMJD3), as shown in EBVassociated Hodgkin's lymphoma (108). However, the apparent up-regulation of JMJD3 was not observable in another study infecting EBV in EBV-negative BL cell lines (109). Meanwhile, global losses of $\mathrm{H} 3 \mathrm{~K} 9 \mathrm{me} 3$ and H4K20me3 were also observed in LCLs (107). The reduction of H3K27me3 and H3K9me3 was further shown to be associated with down-regulation of a cluster of HOX and ZNF genes, respectively (107). However, similar to NPC, a great number of SEs were identified to regulate gene expression in LCLs (110). By analyzing ChIP-Seq data, Hufeng and colleagues showed that the enhancer regions of some oncogenes harbor significantly higher signals of NFKB subunits (RelA/B, cRel, p52, and p50), TFs, H3K27ac, and EBNAs (EBNA2, EBNALP, and EBNA3A/C) and these regions were, therefore, classified as EBV super-enhancers (EBV-SEs) (110). Some oncogenes associated with EBV-SEs, including MYC and BCL2, were further shown to be excessively upregulated (110). In fact, poor clinical outcomes for lymphomas patients with co-expression of MYC and BCL2 were previously reported (111). The epigenetic regulation of gene expression by EBV was further supported by Kostas et al., showing that the expression of a pro-apoptotic protein, BIM, was significantly inhibited in EBV-infected B cells and was associated with reduced promoter acetylation on histones $\mathrm{H} 3(\mathrm{~K} 9, \mathrm{~K} 14)$ and $\mathrm{H} 4$ (K5, K8, K12, and K16), increased H3K27me, and DNA methylation (112). Subsequently, EBNA3A/C was demonstrated to recruit EZH2 and SUZ12 (PRC2 subunits) to regulate histone bivalent switches in the promoter region of BIM, showing gain of H3K27me3 without changing H3K4me3, leading to downregulation of BIM (109). This study has further shown that $\mathrm{EZH} 2, \mathrm{SUZ12}$, and EBNA3C were enriched at the BIM promoter region (109). The down-regulation of BIM may be due to the inhibition of phosphorylation of Pol II by the presence of EBNA3A/C (109). Also, EBNA3A and EBNA3C can be coimmunoprecipitated, suggesting these EBNAs may act directly on the site with the PRC2 complex for the aberrant histone modifications at BIM promoters (109) (Figure 3). As MYC could trigger apoptosis by inducing BIM, inactivating BIM by
EBV could alleviate the BIM-mediated apoptotic stress and, hence, promote carcinogenesis $(113,114)$. The importance of EBNA3A/C in suppression of another TSG, p16 (CDKN2A), was highlighted by Lenka and colleagues as well (115). They observed that the expression of p16 was inhibited in LCLs with the presence of high $\mathrm{H} 3 \mathrm{~K} 27 \mathrm{me} 3$ and low $\mathrm{H} 3 \mathrm{~K} 4 \mathrm{me} 3$ at the corresponding promoter regions, suggesting the involvement of histone bivalent marks. Inactivation of EBNA3A or EBNA3C de-repressed p16 and was associated with reduction of $\mathrm{H} 3 \mathrm{~K} 27 \mathrm{me} 3$ and gain of $\mathrm{H} 3 \mathrm{~K} 4 \mathrm{me} 3$ at the exon 1 region (115). As DNA methylation of CDKN2A promoter was previously reported in LCLs (71), the methylation may be due to the presence of the $\mathrm{H} 3 \mathrm{~K} 27 \mathrm{me} 3$ contributed by the PCR2 complex in which the subunit EZH2 was known to enable recruitment of DNMTs (116). Although C-terminal binding protein (CtBP) was shown to interact with EBNA3A/C in primary rat embryo fibroblasts and the necessity of CtBP to inhibit p16 in LCLs was proven, the interaction of CtBP with EBNA3A/C to inhibit p16 in LCLs needs further investigation (115).

The EBV genome was further shown to interact with the host genome enriched with EBNA1, EBF1, and RBP-jK binding sites (117). Another study found that EBV interacts with repressive compartments of the host genome during latency, but with active compartments during lytic reactivation (118) in BL cell lines. Strikingly, although EBV and host genome interaction sites are similar to those demonstrated in EBVaGC exhibiting A-T rich content, this interaction in $\mathrm{BL}$ is usually enriched with $\mathrm{H} 3 \mathrm{~K} 9 \mathrm{me} 3$, and, hence, inhibits gene expression $(106,117)$. This implies that the EBV episome interacting with the host genome in epithelial and $\mathrm{B}$ cells results in different influence on gene expression. While the interaction in GC induces gene expression through reduction of $\mathrm{H} 3 \mathrm{~K} 9 \mathrm{me} 3$ and is associated with active marks (H3K27ac or $\mathrm{H} 3 \mathrm{~K} 4 \mathrm{me} 1$ ), the interaction in $\mathrm{BL}$ via EBNA1 binding results in repressive of gene expression and is associated with H3K9me3 (106, 117). Figure 3 summarizes the EBNA-associated mechanisms to regulate the host histone status and gene expression.

\section{CONCLUSIONS}

To summarize, it is evident that EBV infection results in hypermethylation in NPC and EBVaGC, driven by LMP1 and LMP2A, respectively, and is associated with down-regulation of TSGs. Although promoter methylation of a few TGSs in EBVinfected B cells is observable, it is unlikely that EBV contributes to global hypermethylation in B cells. With regard to the histone modification status, while $\mathrm{H} 3 \mathrm{~K} 27 \mathrm{me} 3$ is globally prevalent in NPC, a critical elevation level of $\mathrm{H} 3 \mathrm{~K} 27 \mathrm{me} 3$ is not obvious in EBVaGC and EBV-infected B cells. The distinct methylation and histone modification status in the relevant cancer types is summarized in Table 1. Also, histone bivalent switches in NPC and LCLs are critical to regulate gene expression and it is probably contributed by the EBNAs activities. It is also evident that EBV utilizes the host factors to restrict the viral gene expression to evade immune surveillance. Moreover, while interaction of EBV and the host genome is associated with 
TABLE 1 | Methylation and histone modification features for NPC, EBVaGC, LCLs, and BL.

\begin{tabular}{|c|c|c|c|c|}
\hline $\begin{array}{l}\text { Cancer } \\
\text { types }\end{array}$ & $\begin{array}{l}\text { Latency } \\
\text { program }\end{array}$ & Distinct methylation status & Distinct histone modifications & Ref. \\
\hline NPC & $\|$ & Global hypermethylation including critical TSGS & Globally enhanced H3K27me3 & $\begin{array}{c}(19,25-43 \\
99)\end{array}$ \\
\hline EBVaGC & $\begin{array}{l}\text { I (>50\% express } \\
\text { LMP2A) }\end{array}$ & Global hypermethylation including critical TSGs & $\begin{array}{l}\text { Reduction of H3K27me3 around TSS; } \\
\text { EBV genome interacts with host genome in which } \\
\text { H3K9me3 is less frequent, while H3K27ac or } \\
\text { H3K4me1 is enriched to activate gene expression }\end{array}$ & $\begin{array}{l}(20,47-62 \\
68,106)\end{array}$ \\
\hline LCLs & III & $\begin{array}{l}\text { Global hypomethylation including B cell activation genes, and } \\
\text { hypermethylation of TSGs }\end{array}$ & $\begin{array}{l}\text { Global reduction of } \mathrm{H} 3 \mathrm{~K} 27 \mathrm{me} 3, \mathrm{H} 3 \mathrm{~K} 9 \mathrm{me} 3 \text {, and } \\
\text { H4K20me3 }\end{array}$ & $\begin{array}{c}(18,69-71 \\
107)\end{array}$ \\
\hline $\mathrm{BL}$ & 1 & $\begin{array}{l}\text { Global hypomethylation; hypomethylation near promoters while } \\
\text { hypermethylation is distant from TSS }\end{array}$ & $\begin{array}{l}\text { EBV genome interacts with host genome in which } \\
\text { H3K9me3 is enriched to suppress gene } \\
\text { expression }\end{array}$ & $\begin{array}{l}(17,72,106 \\
117,118)\end{array}$ \\
\hline
\end{tabular}

elevation of activation marks to allow gene expression in EBVaGC, such interaction in BL cells is evident with enhanced $\mathrm{H} 3 \mathrm{~K} 9 \mathrm{me} 3$ to suppress gene expression. The currently available EBV epigenetic studies convincingly suggested that EBV utilizes different mechanisms to hijack the host epigenetic system in different tissue types, highlighting the critical role of EBV latent proteins LMP1, LMP2A, and EBNA3C in NPC, EBVaGC, and EBV-associated lymphomas, respectively. Therefore, precisely targeting of different LMPs and EBNAs in different malignant tissues may restore these epigenetic abnormalities and, hence, improve the epigenetic therapies.

\section{REFERENCES}

1. Epstein MA, Achong BG, Barr YM. Virus Particles in Cultured Lymphoblasts from Burkitt's Lymphoma. Lancet (1964) 1(7335):702-3. doi: 10.1016/S0140-6736(64)91524-7

2. Lieberman PM. Keeping it quiet: chromatin control of gammaherpesvirus latency. Nat Rev Microbiol (2013) 11(12):863-75. doi: 10.1038/nrmicro3135

3. Guo R, Jiang C, Zhang Y, Govande A, Wolinsky E, Trudeau SJ, et al. MYC Controls the Epstein-Barr Virus Lytic Switch. Submitted To Mol Cell (2019) 78(4):653-69.e8. doi: 10.1016/j.molcel.2020.03.025

4. Shannon-Lowe C, Rickinson A. The Global Landscape of EBV-Associated Tumors. Front Oncol (2019) 9:713. doi: 10.3389/fonc.2019.00713

5. Young LS, Rickinson AB. Epstein-Barr virus: 40 years on. Nat Rev Cancer (2004) 4(10):757-68. doi: 10.1038/nrc1452

6. Wang D, Liebowitz D, Kieff E. An EBV membrane protein expressed in immortalized lymphocytes transforms established rodent cells. Cell (1985) 43(3 Pt 2):831-40. doi: 10.1016/0092-8674(85)90256-9

7. Kaye KM, Izumi KM, Kieff E. Epstein-Barr virus latent membrane protein 1 is essential for B-lymphocyte growth transformation. Proc Natl Acad Sci USA (1993) 90(19):9150-4. doi: 10.1073/pnas.90.19.9150

8. Tsao SW, Tramoutanis G, Dawson CW, Lo AK, Huang DP. The significance of LMP1 expression in nasopharyngeal carcinoma. Semin Cancer Biol (2002) 12(6):473-87. doi: 10.1016/S1044579X02000901

9. Sharma S, Kelly TK, Jones PA. Epigenetics in cancer. Carcinogenesis (2010) 31(1):27-36. doi: 10.1093/carcin/bgp220

10. Jones PA, Baylin SB. The epigenomics of cancer. Cell (2007) 128(4):683-92. doi: 10.1016/j.cell.2007.01.029

11. Lu F, Tempera I, Lee HT, Dewispelaere K, Lieberman PM. EBNA1 binding and epigenetic regulation of gastrokine tumor suppressor genes in gastric carcinoma cells. Virol J (2014) 11:12. doi: 10.1186/1743-422X-11-12

12. Tempera I, De Leo A, Kossenkov AV, Cesaroni M, Song H, Dawany N, et al. Identification of MEF2B, EBF1, and IL6R as Direct Gene Targets of EpsteinBarr Virus (EBV) Nuclear Antigen 1 Critical for EBV-Infected B-Lymphocyte Survival. J Virol (2016) 90(1):345-55. doi: 10.1128/JVI.02318-15

\section{AUTHOR CONTRIBUTIONS}

MML: conceptualized and wrote the manuscript. MLL: guidelines and proofreading. All authors contributed to the article and approved the submitted version.

\section{ACKNOWLEDGMENTS}

The authors sincerely acknowledge Momoka Nakada who inspired them to draw the figures.

13. O’Neil JD, Owen TJ, Wood VHJ, Date KL, Valentine R, Chukwuma MB, et al. Epstein-Barr virus-encoded EBNA1 modulates the AP-1 transcription factor pathway in nasopharyngeal carcinoma cells and enhances angiogenesis in vitro. J Gen Virol (2008) 89(Pt 11):2833-42. doi: 10.1099/ vir.0.2008/003392-0

14. Abdallah MOE, Algizouli UK, Suliman MA, Abdulrahman RA, Koko M, Fessahaye G, et al. EBV Associated Breast Cancer Whole Methylome Analysis Reveals Viral and Developmental Enriched Pathways. Front Oncol (2018) 8:316. doi: 10.3389/fonc.2018.00316

15. Yahia ZA, Adam AA, Elgizouli M, Hussein A, Masri MA, Kamal M, et al. Epstein Barr virus: a prime candidate of breast cancer aetiology in Sudanese patients. Infect Agent Cancer (2014) 9(1):9. doi: 10.1186/1750-9378-9-9

16. Dhiab MB, Ziadi S, Mestiri S, Gacem RB, Ksiaa F, Trimeche M. DNA methylation patterns in EBV-positive and EBV-negative Hodgkin lymphomas. Cell Oncol (Dordr) (2015) 38(6):453-62. doi: 10.1007/s13402015-0242-8

17. Hernandez-Vargas H, Gruffat H, Cros MP, Diederichs A, Sirand C, VargasAyala RC, et al. Viral driven epigenetic events alter the expression of cancerrelated genes in Epstein-Barr-virus naturally infected Burkitt lymphoma cell lines. Sci Rep (2017) 7(1):5852. doi: 10.1038/s41598-017-05713-2

18. Hansen KD, Sabunciyan S, Langmead B, Nagy N, Curley R, Klein G, et al. Large-scale hypomethylated blocks associated with Epstein-Barr virusinduced B-cell immortalization. Genome Res (2014) 24(2):177-84. doi: $10.1101 /$ gr.157743.113

19. Dai W, Cheung AK, Ko JM, Cheng Y, Zheng H, Ngan RK, et al. Comparative methylome analysis in solid tumors reveals aberrant methylation at chromosome $6 \mathrm{p}$ in nasopharyngeal carcinoma. Cancer Med (2015) 4 (7):1079-90. doi: 10.1002/cam4.451

20. Matsusaka K, Kaneda A, Nagae G, Ushiku T, Kikuchi Y, Hino R, et al. Classification of Epstein-Barr virus-positive gastric cancers by definition of DNA methylation epigenotypes. Cancer Res (2011) 71(23):7187-97. doi: 10.1158/0008-5472.CAN-11-1349

21. Moore LD, Le T, Fan G. DNA methylation and its basic function. Neuropsychopharmacology (2013) 38(1):23-38. doi: 10.1038/npp.2012.112 
22. Wu X, Zhang Y. TET-mediated active DNA demethylation: mechanism, function and beyond. Nat Rev Genet (2017) 18(9):517-34. doi: 10.1038/ nrg. 2017.33

23. Saxonov S, Berg P, Brutlag DL. A genome-wide analysis of CpG dinucleotides in the human genome distinguishes two distinct classes of promoters. Proc Natl Acad Sci (2006) 103(5):1412-7. doi: 10.1073/ pnas.0510310103

24. Baylin SB. DNA methylation and gene silencing in cancer. Nat Clin Pract Oncol (2005) 2 Suppl 1:S4-11. doi: 10.1038/ncponc0354

25. Zhao W, Mo Y, Wang S, Midorikawa K, Ma N, Hiraku Y, et al. Quantitation of DNA methylation in Epstein-Barr virus-associated nasopharyngeal carcinoma by bisulfite amplicon sequencing. BMC Cancer (2017) 17 (1):489. doi: 10.1186/s12885-017-3482-3

26. Lo KW, Kwong J, Hui AB, Chan SY, To KF, Chan AS, et al. High frequency of promoter hypermethylation of RASSF1A in nasopharyngeal carcinoma. Cancer Res (2001) 61(10):3877-81.

27. Chow LSN, Lo KW, Kwong J, To KF, Tsang KS, Lam CW, et al. RASSF1A is a target tumor suppressor from $3 \mathrm{p} 21.3$ in nasopharyngeal carcinoma. Int J Cancer (2004) 109(6):839-47. doi: 10.1002/ijc.20079

28. Cheng Y, Stanbridge EJ, Kong H, Bengtsson U, Lerman MI, Lung ML. A functional investigation of tumor suppressor gene activities in a nasopharyngeal carcinoma cell line HONE1 using a monochromosome transfer approach. Genes Chromosomes Cancer (2000) 28(1):82-91. doi: 10.1002/(SICI)1098-2264(200005)28:1<82::AID-GCC10>3.0.CO;2-8

29. Lo KW, Cheung ST, Leung SF, van Hasselt A, Tsang YS, Mak KF, et al. Hypermethylation of the p16 gene in nasopharyngeal carcinoma. Cancer Res (1996) 56(12):2721-5.

30. Wang GL, Lo KW, Tsang KS, Chung NY, Tsang YS, Cheung ST, et al. Inhibiting tumorigenic potential by restoration of p16 in nasopharyngeal carcinoma. Br J Cancer (1999) 81(7):1122-6. doi: $10.1038 /$ sj.bjc. 6690818

31. Cheung AK, Lung HL, Ko JM, Cheng Y, Stanbridge EJ, Zabarovsky ER, et al. Chromosome 14 transfer and functional studies identify a candidate tumor suppressor gene, mirror image polydactyly 1, in nasopharyngeal carcinoma. Proc Natl Acad Sci U S A (2009) 106(34):14478-83. doi: 10.1073/ pnas.0900198106

32. Leong MML, Cheung AKL, Kwok TCT, Lung ML. Functional characterization of a candidate tumor suppressor gene, Mirror Image Polydactyly 1, in nasopharyngeal carcinoma. Int J Cancer (2020) 146 (10):2891-900. doi: 10.1002/ijc.32732

33. Cheung AK, Ip JC, Chu AC, Cheng Y, Leong MM, Ko JM, et al. PTPRG suppresses tumor growth and invasion via inhibition of Akt signaling in nasopharyngeal carcinoma. Oncotarget (2015) 6(15):13434-47. doi: 10.18632/oncotarget.3876

34. Cheung AK, Lung HL, Hung SC, Law EW, Cheng Y, Yau WL, et al. Functional analysis of a cell cycle-associated, tumor-suppressive gene, protein tyrosine phosphatase receptor type G, in nasopharyngeal carcinoma. Cancer Res (2008) 68(19):8137-45. doi: 10.1158/00085472.CAN-08-0904

35. Mo Y, Midorikawa K, Zhang Z, Zhou X, Ma N, Huang G, et al. Promoter hypermethylation of Ras-related GTPase gene RRAD inactivates a tumor suppressor function in nasopharyngeal carcinoma. Cancer Lett (2012) 323 (2):147-54. doi: 10.1016/j.canlet.2012.03.042

36. Lung HL, Bangarusamy DK, Xie D, Cheung AK, Cheng Y, Kumaran MK, et al. THY1 is a candidate tumour suppressor gene with decreased expression in metastatic nasopharyngeal carcinoma. Oncogene (2005) 24 (43):6525-32. doi: 10.1038/sj.onc.1208812

37. Lung HL, Cheung AK, Cheng Y, Kwong FM, Lo PH, Law EW, et al. Functional characterization of THY1 as a tumor suppressor gene with antiinvasive activity in nasopharyngeal carcinoma. Int J Cancer (2010) 127 (2):304-12. doi: 10.1002/ijc.25047

38. Li J, Gong P, Lyu X, Yao K, Li X, Peng H. Aberrant CpG island methylation of PTEN is an early event in nasopharyngeal carcinoma and a potential diagnostic biomarker. Oncol Rep (2014) 31(5):2206-12. doi: 10.3892/ or.2014.3061

39. Xu X, Yang H, Huo X. [Expression and significance of PTEN in nasopharyngeal carcinoma]. Lin Chuang Er Bi Yan Hou Ke Za Zhi (2004) 18(11):658-9.
40. Zheng Z, Pan J, Chu B, Wong YC, Cheung AL, Tsao SW. Downregulation and abnormal expression of E-cadherin and beta-catenin in nasopharyngeal carcinoma: close association with advanced disease stage and lymph node metastasis. Hum Pathol (1999) 30(4):458-66. doi: 10.1016/S0046-8177(99) 90123-5

41. Tsao SW, Liu Y, Wang X, Yuen PW, Leung SY, Yuen ST, et al. The association of E-cadherin expression and the methylation status of the Ecadherin gene in nasopharyngeal carcinoma cells. Eur J Cancer (2003) 39 (4):524-31. doi: 10.1016/S0959-8049(02)00494-X

42. Seo SY, Kim EO, Jang KL. Epstein-Barr virus latent membrane protein 1 suppresses the growth-inhibitory effect of retinoic acid by inhibiting retinoic acid receptor-beta2 expression via DNA methylation. Cancer Lett (2008) 270 (1):66-76. doi: 10.1016/j.canlet.2008.04.043

43. Kwong J, Lo KW, To KF, Teo PM, Johnson PJ, Huang DP. Promoter hypermethylation of multiple genes in nasopharyngeal carcinoma. Clin Cancer Res (2002) 8(1):131-7.

44. Tsai CL, Li HP, Lu YJ, Hsueh C, Liang Y, Chen CL, et al. Activation of DNA methyltransferase 1 by EBV LMP1 Involves c-Jun NH(2)-terminal kinase signaling. Cancer Res (2006) 66(24):11668-76. doi: 10.1158/00085472.CAN-06-2194

45. Tsai CN, Tsai CL, Tse KP, Chang HY, Chang YS. The Epstein-Barr virus oncogene product, latent membrane protein 1, induces the downregulation of E-cadherin gene expression via activation of DNA methyltransferases. Proc Natl Acad Sci U S A (2002) 99(15):10084-9. doi: 10.1073/ pnas. 152059399

46. Peng H, Chen Y, Gong P, Cai L, Lyu X, Jiang Q, et al. Higher methylation intensity induced by EBV LMP1 via NF-kappaB/DNMT3b signaling contributes to silencing of PTEN gene. Oncotarget (2016) 7(26):40025-37. doi: 10.18632/oncotarget.9474

47. Cancer Genome Atlas Research N. Comprehensive molecular characterization of gastric adenocarcinoma. Nature (2014) 513 (7517):202-9. doi: 10.1038/nature13480

48. Kang GH, Lee S, Kim WH, Lee HW, Kim JC, Rhyu MG, et al. Epstein-barr virus-positive gastric carcinoma demonstrates frequent aberrant methylation of multiple genes and constitutes $\mathrm{CpG}$ island methylator phenotype-positive gastric carcinoma. Am J Pathol (2002) 160(3):787-94. doi: 10.1016/S0002-9440(10)64901-2

49. Vo QN, Geradts J, Gulley ML, Boudreau DA, Bravo JC, Schneider BG. Epstein-Barr virus in gastric adenocarcinomas: association with ethnicity and CDKN2A promoter methylation. J Clin Pathol (2002) 55(9):669-75. doi: 10.1136/jcp.55.9.669

50. Ferrasi AC, Pinheiro NA, Rabenhorst SH, Caballero OL, Rodrigues MA, de Carvalho F, et al. Helicobacter pylori and EBV in gastric carcinomas: methylation status and microsatellite instability. World J Gastroenterol (2010) 16(3):312-9. doi: 10.3748/wjg.v16.i3.312

51. Geddert H, Zur Hausen A, Gabbert HE, Sarbia M. EBV-infection in cardiac and non-cardiac gastric adenocarcinomas is associated with promoter methylation of p16, p14 and APC, but not hMLH1. Anal Cell Pathol (Amst) (2010) 33(3):143-9. doi: 10.1155/2010/453764

52. Saito M, Nishikawa J, Okada T, Morishige A, Sakai K, Nakamura M, et al. Role of DNA methylation in the development of Epstein-Barr virusassociated gastric carcinoma. J Med Virol (2013) 85(1):121-7. doi: 10.1002/jmv.23405

53. He D, Zhang YW, Zhang NN, Zhou L, Chen JN, Jiang Y, et al. Aberrant gene promoter methylation of p16, FHIT, CRBP1, WWOX, and DLC-1 in Epstein-Barr virus-associated gastric carcinomas. Med Oncol (2015) 32 (4):92. doi: 10.1007/s12032-015-0525-y

54. Ryan JL, Jones RJ, Kenney SC, Rivenbark AG, Tang W, Knight ER, et al. Epstein-Barr virus-specific methylation of human genes in gastric cancer cells. Infect Agent Cancer (2010) 5:27. doi: 10.1186/1750-9378-5-27

55. Chong JM, Sakuma K, Sudo M, Ushiku T, Uozaki H, Shibahara J, et al. Global and non-random CpG-island methylation in gastric carcinoma associated with Epstein-Barr virus. Cancer Sci (2003) 94(1):76-80. doi: 10.1111/j.1349-7006.2003.tb01355.x

56. Chang MS, Uozaki H, Chong JM, Ushiku T, Sakuma K, Ishikawa S, et al. CpG island methylation status in gastric carcinoma with and without infection of Epstein-Barr virus. Clin Cancer Res (2006) 12(10):2995-3002. doi: 10.1158/1078-0432.CCR-05-1601 
57. Dong SM, Lee HG, Cho SG, Kwon SH, Yoon H, Kwon HJ, et al. Hypermethylation of the interferon regulatory factor 5 promoter in Epstein-Barr virus-associated gastric carcinoma. J Microbiol (2015) 53 (1):70-6. doi: 10.1007/s12275-014-4654-3

58. Okada T, Nakamura M, Nishikawa J, Sakai K, Zhang Y, Saito M, et al. Identification of genes specifically methylated in Epstein-Barr virusassociated gastric carcinomas. Cancer Sci (2013) 104(10):1309-14. doi: $10.1111 /$ cas. 12228

59. Sakuma K, Chong JM, Sudo M, Ushiku T, Inoue Y, Shibahara J, et al. Highdensity methylation of p14ARF and p16INK4A in Epstein-Barr virusassociated gastric carcinoma. Int J Cancer (2004) 112(2):273-8. doi: $10.1002 / \mathrm{ijc} .20420$

60. Liu X, Wang Y, Wang X, Sun Z, Li L, Tao Q, et al. Epigenetic silencing of WNT5A in Epstein-Barr virus-associated gastric carcinoma. Arch Virol (2013) 158(1):123-32. doi: 10.1007/s00705-012-1481-x

61. Hino R, Uozaki H, Murakami N, Ushiku T, Shinozaki A, Ishikawa S, et al. Activation of DNA methyltransferase 1 by EBV latent membrane protein $2 \mathrm{~A}$ leads to promoter hypermethylation of PTEN gene in gastric carcinoma. Cancer Res (2009) 69(7):2766-74. doi: 10.1158/0008-5472.CAN-08-3070

62. Sudo M, Chong JM, Sakuma K, Ushiku T, Uozaki H, Nagai H, et al. Promoter hypermethylation of E-cadherin and its abnormal expression in Epstein-Barr virus-associated gastric carcinoma. Int J Cancer (2004) 109 (2):194-9. doi: 10.1002/ijc.11701

63. Etoh T, Kanai Y, Ushijima S, Nakagawa T, Nakanishi Y, Sasako M, et al. Increased DNA methyltransferase 1 (DNMT1) protein expression correlates significantly with poorer tumor differentiation and frequent DNA hypermethylation of multiple $\mathrm{CpG}$ islands in gastric cancers. Am J Pathol (2004) 164(2):689-99. doi: 10.1016/S0002-9440(10)63156-2

64. Wang J, Liu W, Zhang X, Zhang Y, Xiao H, Luo B. LMP2A induces DNA methylation and expression repression of AQP3 in EBV-associated gastric carcinoma. Virology (2019) 534:87-95. doi: 10.1016/j.virol.2019.06.006

65. Satooka H, Hara-Chikuma M. Aquaporin-3 Controls Breast Cancer Cell Migration by Regulating Hydrogen Peroxide Transport and Its Downstream Cell Signaling. Mol Cell Biol (2016) 36(7):1206-18. doi: 10.1128/ MCB.00971-15

66. Fukayama M, Abe H, Kunita A, Shinozaki-Ushiku A, Matsusaka K, Ushiku T, et al. Thirty years of Epstein-Barr virus-associated gastric carcinoma. Virchows Arch (2020) 476(3):353-65. doi: 10.1007/s00428-019-02724-4

67. Namba-Fukuyo H, Funata S, Matsusaka K, Fukuyo M, Rahmutulla B, Mano Y, et al. TET2 functions as a resistance factor against DNA methylation acquisition during Epstein-Barr virus infection. Oncotarget (2016) 7 (49):81512-26. doi: 10.18632/oncotarget.13130

68. Okabe A, Funata S, Matsusaka K, Namba H, Fukuyo M, Rahmutulla B, et al. Regulation of tumour related genes by dynamic epigenetic alteration at enhancer regions in gastric epithelial cells infected by Epstein-Barr virus. Sci Rep (2017) 7(1):7924. doi: 10.1038/s41598-017-08370-7

69. Hernando H, Shannon-Lowe C, Islam AB, Al-Shahrour F, RodriguezUbreva J, Rodriguez-Cortez VC, et al. The B cell transcription program mediates hypomethylation and overexpression of key genes in Epstein-Barr virus-associated proliferative conversion. Genome Biol (2013) 14(1):R3. doi: 10.1186/gb-2013-14-1-r3

70. Zhang C, Zhang R, Chen Z, Chen J, Ruan J, Lu Z, et al. Differential DNA methylation profiles of human B lymphocytes and Epstein-Barr virusimmortalized B lymphocytes. Chin J Cancer Res (2018) 30(1):104-11. doi: 10.21147/j.issn.1000-9604.2018.01.11

71. Saha A, Jha HC, Upadhyay SK, Robertson ES. Epigenetic silencing of tumor suppressor genes during in vitro Epstein-Barr virus infection. Proc Natl Acad Sci U S A (2015) 112(37):E5199-207. doi: 10.1073/pnas.1503806112

72. Kretzmer H, Bernhart SH, Wang W, Haake A, Weniger MA, Bergmann AK, et al. DNA methylome analysis in Burkitt and follicular lymphomas identifies differentially methylated regions linked to somatic mutation and transcriptional control. Nat Genet (2015) 47(11):1316-25. doi: 10.1038/ ng.3413

73. Pandey S, Robertson ES. Oncogenic Epstein-Barr virus recruits Nm23-H1 to regulate chromatin modifiers. Lab Invest (2018) 98(2):258-68. doi: 10.1038/ labinvest.2017.112

74. Zhang S, Pei Y, Lang F, Sun K, Singh RK, Lamplugh ZL, et al. EBNA3C facilitates RASSF1A downregulation through ubiquitin-mediated degradation and promoter hypermethylation to drive B-cell proliferation. PloS Pathog (2019) 15(1):e1007514. doi: 10.1371/journal.ppat.1007514

75. Leonard S, Wei W, Anderton J, Vockerodt M, Rowe M, Murray PG, et al. Epigenetic and transcriptional changes which follow Epstein-Barr virus infection of germinal center $B$ cells and their relevance to the pathogenesis of Hodgkin's lymphoma. J Virol (2011) 85(18):9568-77. doi: 10.1128/ JVI.00468-11

76. Guo R, Zhang Y, Teng M, Jiang C, Schineller M, Zhao B, et al. DNA methylation enzymes and PRC1 restrict B-cell Epstein-Barr virus oncoprotein expression. Nat Microbiol (2020) 5(8):1051-63. doi: 10.1038/ s41564-020-0724-y

77. Zhao Z, Shilatifard A. Epigenetic modifications of histones in cancer. Genome Biol (2019) 20(1):245. doi: 10.1186/s13059-019-1870-5

78. Audia JE, Campbell RM. Histone Modifications and Cancer. Cold Spring Harb Perspect Biol (2016) 8(4):a019521. doi: 10.1101/cshperspect.a019521

79. Kouzarides T. Chromatin modifications and their function. Cell (2007) 128 (4):693-705. doi: 10.1016/j.cell.2007.02.005

80. Shilatifard A. Chromatin modifications by methylation and ubiquitination: implications in the regulation of gene expression. Annu Rev Biochem (2006) 75:243-69. doi: 10.1146/annurev.biochem.75.103004.142422

81. Bannister AJ, Kouzarides T. Regulation of chromatin by histone modifications. Cell Res (2011) 21(3):381-95. doi: 10.1038/cr.2011.22

82. Creyghton MP, Cheng AW, Welstead GG, Kooistra T, Carey BW, Steine EJ, et al. Histone $\mathrm{H} 3 \mathrm{~K} 27 \mathrm{ac}$ separates active from poised enhancers and predicts developmental state. Proc Natl Acad Sci USA (2010) 107(50):21931-6. doi: 10.1073/pnas.1016071107

83. Struhl K. Histone acetylation and transcriptional regulatory mechanisms. Genes Dev (1998) 12(5):599-606. doi: 10.1101/gad.12.5.599

84. Peserico A, Simone C. Physical and functional HAT/HDAC interplay regulates protein acetylation balance. J BioMed Biotechnol (2011) 2011:371832. doi: 10.1155/2011/371832

85. Black JC, Van Rechem C, Whetstine JR. Histone lysine methylation dynamics: establishment, regulation, and biological impact. Mol Cell (2012) 48(4):491-507. doi: 10.1016/j.molcel.2012.11.006

86. Shi Y. Histone lysine demethylases: emerging roles in development, physiology and disease. Nat Rev Genet (2007) 8(11):829-33. doi: 10.1038/ nrg2218

87. Pirrotta V. Polycombing the genome: PcG, trxG, and chromatin silencing. Cell (1998) 93(3):333-6. doi: 10.1016/S0092-8674(00)81162-9

88. Hyun K, Jeon J, Park K, Kim J. Writing, erasing and reading histone lysine methylations. Exp Mol Med (2017) 49(4):e324. doi: 10.1038/emm.2017.11

89. Voigt P, Tee WW, Reinberg D. A double take on bivalent promoters. Genes $\operatorname{Dev}(2013)$ 27(12):1318-38. doi: 10.1101/gad.219626.113

90. Bernstein BE, Mikkelsen TS, Xie X, Kamal M, Huebert DJ, Cuff J, et al. A bivalent chromatin structure marks key developmental genes in embryonic stem cells. Cell (2006) 125(2):315-26. doi: 10.1016/j.cell.2006.02.041

91. Bernhart SH, Kretzmer H, Holdt LM, Juhling F, Ammerpohl O, Bergmann $\mathrm{AK}$, et al. Changes of bivalent chromatin coincide with increased expression of developmental genes in cancer. Sci Rep (2016) 6:37393. doi: 10.1038/ srep37393

92. Lin B, Lee H, Yoon JG, Madan A, Wayner E, Tonning S, et al. Global analysis of $\mathrm{H} 3 \mathrm{~K} 4 \mathrm{me} 3$ and $\mathrm{H} 3 \mathrm{~K} 27 \mathrm{me} 3$ profiles in glioblastoma stem cells and identification of SLC17A7 as a bivalent tumor suppressor gene. Oncotarget (2015) 6(7):5369-81. doi: 10.18632/oncotarget.3030

93. Zaidi SK, Frietze SE, Gordon JA, Heath JL, Messier T, Hong D, et al. Bivalent Epigenetic Control of Oncofetal Gene Expression in Cancer. Mol Cell Biol (2017) 37(23):e00352-17. doi: 10.1128/MCB.00352-17

94. Rodriguez J, Munoz M, Vives L, Frangou CG, Groudine M, Peinado MA. Bivalent domains enforce transcriptional memory of DNA methylated genes in cancer cells. Proc Natl Acad Sci U S A (2008) 105(50):19809-14. doi: 10.1073/pnas.0810133105

95. Gurley LR, Walters RA, Tobey RA. Cell cycle-specific changes in histone phosphorylation associated with cell proliferation and chromosome condensation. J Cell Biol (1974) 60(2):356-64. doi: 10.1083/jcb.60.2.356

96. Kim HG, Lee KW, Cho YY, Kang NJ, Oh SM, Bode AM, et al. Mitogen- and stress-activated kinase 1-mediated histone $\mathrm{H} 3$ phosphorylation is crucial for cell transformation. Cancer Res (2008) 68(7):2538-47. doi: 10.1158/00085472.CAN-07-6597 
97. Alghamdi TA, Batchu SN, Hadden MJ, Yerra VG, Liu Y, Bowskill BB, et al. Histone H3 Serine 10 Phosphorylation Facilitates Endothelial Activation in Diabetic Kidney Disease. Diabetes (2018) 67(12):2668-81. doi: 10.2337/db18-0124

98. Choi HS, Choi BY, Cho YY, Mizuno H, Kang BS, Bode AM, et al. Phosphorylation of histone $\mathrm{H} 3$ at serine 10 is indispensable for neoplastic cell transformation. Cancer Res (2005) 65(13):5818-27. doi: 10.1158/00085472.CAN-05-0197

99. Cai MY, Tong ZT, Zhu W, Wen ZZ, Rao HL, Kong LL, et al. H3K27me3 protein is a promising predictive biomarker of patients' survival and chemoradioresistance in human nasopharyngeal carcinoma. Mol Med (2011) 17(11-12):1137-45. doi: 10.2119/molmed.2011.00054

100. Tong ZT, Cai MY, Wang XG, Kong LL, Mai SJ, Liu YH, et al. EZH2 supports nasopharyngeal carcinoma cell aggressiveness by forming a co-repressor complex with HDAC1/HDAC2 and Snail to inhibit E-cadherin. Oncogene (2012) 31(5):583-94. doi: 10.1038/onc.2011.254

101. Ke L, Zhou H, Wang C, Xiong G, Xiang Y, Ling Y, et al. Nasopharyngeal carcinoma super-enhancer-driven ETV6 correlates with prognosis. Proc Natl Acad Sci USA (2017) 114(36):9683-8. doi: 10.1073/pnas.1705236114

102. Li B, Huang G, Zhang X, Li R, Wang J, Dong Z, et al. Increased phosphorylation of histone $\mathrm{H} 3$ at serine 10 is involved in Epstein-Barr virus latent membrane protein-1-induced carcinogenesis of nasopharyngeal carcinoma. BMC Cancer (2013) 13:124. doi: 10.1186/1471-2407-13-124

103. Leong MML, Cheung AKL, Dai W, Tsao SW, Tsang CM, Dawson CW, et al. EBV infection is associated with histone bivalent switch modifications in squamous epithelial cells. Proc Natl Acad Sci USA (2019) 116(28):14144-53. doi: $10.1073 /$ pnas.1821752116

104. Funata S, Matsusaka K, Yamanaka R, Yamamoto S, Okabe A, Fukuyo M, et al. Histone modification alteration coordinated with acquisition of promoter DNA methylation during Epstein-Barr virus infection. Oncotarget (2017) 8(33):55265-79. doi: 10.18632/oncotarget.19423

105. Asakawa Y, Okabe A, Fukuyo M, Li W, Ikeda E, Mano Y, et al. Epstein-Barr virus-positive gastric cancer involves enhancer activation through activating transcription factor 3. Cancer Sci (2020) 111(5):1818-28. doi: 10.1111/cas.14370

106. Okabe A, Huang KK, Matsusaka K, Fukuyo M, Xing M, Ong X, et al. Crossspecies chromatin interactions drive transcriptional rewiring in Epstein-Barr virus-positive gastric adenocarcinoma. Nat Genet (2020) 52(9):919-30. doi: 10.1038/s41588-020-0665-7

107. Hernando H, Islam AB, Rodriguez-Ubreva J, Forne I, Ciudad L, Imhof A, et al. Epstein-Barr virus-mediated transformation of B cells induces global chromatin changes independent to the acquisition of proliferation. Nucleic Acids Res (2014) 42(1):249-63. doi: 10.1093/nar/gkt886

108. Anderton JA, Bose S, Vockerodt M, Vrzalikova K, Wei W, Kuo M, et al. The H3K27me3 demethylase, KDM6B, is induced by Epstein-Barr virus and over-expressed in Hodgkin's Lymphoma. Oncogene (2011) 30(17):2037-43. doi: 10.1038/onc.2010.579

109. Paschos K, Parker GA, Watanatanasup E, White RE, Allday MJ. BIM promoter directly targeted by EBNA3C in polycomb-mediated repression by EBV. Nucleic Acids Res (2012) 40(15):7233-46. doi: 10.1093/nar/ gks391

110. Zhou H, Schmidt SC, Jiang S, Willox B, Bernhardt K, Liang J, et al. EpsteinBarr virus oncoprotein super-enhancers control B cell growth. Cell Host Microbe (2015) 17(2):205-16. doi: 10.1016/j.chom.2014.12.013

111. Hu S, Xu-Monette ZY, Tzankov A, Green T, Wu L, Balasubramanyam A, et al. MYC/BCL2 protein coexpression contributes to the inferior survival of activated B-cell subtype of diffuse large B-cell lymphoma and demonstrates high-risk gene expression signatures: a report from The International DLBCL Rituximab-CHOP Consortium Program. Blood (2013) 121 (20):4021-31; quiz 250. doi: 10.1182/blood-2012-10-460063

112. Paschos K, Smith P, Anderton E, Middeldorp JM, White RE, Allday MJ. Epstein-barr virus latency in B cells leads to epigenetic repression and $\mathrm{CpG}$ methylation of the tumour suppressor gene Bim. PloS Pathogens (2009) 5(6): e1000492. doi: 10.1371/journal.ppat.1000492

113. Dang CV, O’Donnell KA, Juopperi T. The great MYC escape in tumorigenesis. Cancer Cell (2005) 8(3):177-8. doi: 10.1016/j.ccr.2005.08.005

114. Hemann MT, Bric A, Teruya-Feldstein J, Herbst A, Nilsson JA, CordonCardo C, et al. Evasion of the p53 tumour surveillance network by tumourderived MYC mutants. Nature (2005) 436(7052):807-11. doi: 10.1038/ nature 03845

115. Skalska L, White RE, Franz M, Ruhmann M, Allday MJ. Epigenetic repression of $\mathrm{p} 16$ (INK4A) by latent Epstein-Barr virus requires the interaction of EBNA3A and EBNA3C with CtBP. PloS Pathog (2010) 6(6): e1000951. doi: 10.1371/journal.ppat.1000951

116. Vire E, Brenner C, Deplus R, Blanchon L, Fraga M, Didelot C, et al. The Polycomb group protein EZH2 directly controls DNA methylation. Nature (2006) 439(7078):871-4. doi: 10.1038/nature04431

117. Kim KD, Tanizawa H, De Leo A, Vladimirova O, Kossenkov A, Lu F, et al. Epigenetic specifications of host chromosome docking sites for latent Epstein-Barr virus. Nat Commun (2020) 11(1):877. doi: 10.1038/s41467019-14152-8

118. Moquin SA, Thomas S, Whalen S, Warburton A, Fernandez SG, McBride $A A$, et al. The Epstein-Barr Virus Episome Maneuvers between Nuclear Chromatin Compartments during Reactivation. J Virol (2018) 92(3):e0141317. doi: 10.1128/JVI.01413-17

Conflict of Interest: The authors declare that the research was conducted in the absence of any commercial or financial relationships that could be construed as a potential conflict of interest.

Copyright (c) 2021 Leong and Lung. This is an open-access article distributed under the terms of the Creative Commons Attribution License (CC BY). The use, distribution or reproduction in other forums is permitted, provided the original author(s) and the copyright owner(s) are credited and that the original publication in this journal is cited, in accordance with accepted academic practice. No use, distribution or reproduction is permitted which does not comply with these terms. 